\title{
Analysis of the Effect of Impact Damage on the Repairability of Composite Panels
}

\author{
N. Alzeanidi, H. Ghasemnejad ${ }^{1}$ \\ Centre for Structures, Assembly and Intelligent Automation, \\ Cranfield University, MK43 0AL, UK
}

\begin{abstract}
.
The present paper aims to provide further understanding of the behaviour of Carbon Fibre Reinforced Plastic (CFRP) composite panels under high velocity impact and develop design guideline for repair of damaged composite panels in order to increase the aircraft survivability. This work consists of two parts: part one is a combination of experimental investigation and numerical simulation to evaluate the impact of a woven CFRP laminate which were subjected to selected impact velocities $(100 \mathrm{~m} / \mathrm{s}-500 \mathrm{~m} / \mathrm{s})$ in order to evaluate the induced impact damage in two different thicknesses of CFRP composite panels $(4.125 \mathrm{~mm}$ and $2.625 \mathrm{~mm})$. In part two a finite element model is developed to design a guideline for repairing of a composite panel. In order to achieve this an optimised repair models with variable parameters such as number of steps and length of steps in the stepped lap joints are investigated. The penetration process and also change of kinetic energy absorption characteristics have been used to validate the finite element results. Finite element results were in close agreement with experimental data obtained from different sources.
\end{abstract}

Keywords: High Velocity, Impact, Damage, Repair, LSDYNA

Published by Elsevier. This is the Author Accepted Manuscript issued with:

Creative Commons Attribution Non-Commercial No Derivatives License (CC:BY:NC:ND 3.0).

The final published version (version of record) is available online at DOI:10.1016/j.compstruct.2017.05.054

Please refer to any applicable publisher terms of use.

\footnotetext{
${ }^{1}$ Corresponding Author: email: Hessam.Ghasemnejad@cranfield.ac.uk Tel.:+44 (0) 1234754395.
} 


\section{Introduction}

The use of composite materials in modern military and civil aircraft structures is a continuous increase. At least $50 \%$ of the next generation of military and civil aircraft structures are likely to be made from composite materials as presented by Australian Transport Safety Bureau [1]. Composite materials are used in aircraft because they offer good properties, such as high strength to weight ratio, high capacity to absorb kinetic energy and ease of repair. However, they have low resistance to impact damage caused by threats such as dropped tools or runway debris and this damage can lead to significant strength reductions which affects the aircraft survivability. Aircraft survivability analysts are concerned with protecting aircraft from manmade threats. However, this study has accounted an assessment of the ability of a damaged structure to be repaired quickly as parts of aircraft survivability assessment.

The behaviour of composite structures under impact loading is one of the major concerns in aerospace industry [2]. Bland et. al. [3] performed a wide set of experiments with projectiles impacting CFRP composite, and analysed different types of failures. Olsson et. al. [4] found that impact response is dependent on the projectiles' velocities. Cantwell and Morton [5] presented low and high velocity impact tests to investigate the initiation and development of damage in a number of CFRP panels. Zukas [6] published a book (High Velocity Impact Dynamics) dealing with experimental, analytical, and numerical aspects of the behaviour of materials subjected to high velocity impact.

Failure modelling of composite materials under impact loading by the finite element method (FEM) has been the subject of numerous studies. Abrate [7-8] comprehensively reviewed the ballistic impact of laminated composite materials. Detailed penetration process and damage progressions were simulated with graphite/epoxy laminates impacted by a steel projectile and compared with the experimental results [9].

The high velocity impact of a projectile on aircraft structures of composite materials has been investigated based on experimental techniques and numerical simulation [10-18] to understand and improve the impact response of composite materials and structures. Aambur [19] presented 
a comparison of LS-DYNA numerical simulations and experimental results for a complete penetration test of the thin plates by small fragment impactors. Fujii et. al. [20] performed several kinds of CFRP laminate specimens, which were subjected to a steel sphere having a velocity of $500-1230 \mathrm{~m} / \mathrm{s}$ impact loading. Tanabe et. al. [21] analysed the behaviour of CFRP damaged by the impact of a steel sphere. In their work, effects of interfacial strength and properties on the fracture behaviour of the CFRPs were investigated by energy absorption measurement and in situ morphological observation. Hammond et. al. [22] studied high velocity fibre impact on CFRPs with extensive work to measure in-plane and out-of-plane deformation of the sample during impact, residual velocity of the projectile, as well as microscopic and macroscopic damage. Chan et. al. [23] presented an experimental programme and a computational model in LS-DYNA to determine the ballistic limits of CFRP laminates in various stacking sequences. López-Puente et. al. [24] used a finite element numerical model for carbon/epoxy composite to predict both residual velocity and damaged area when subjected to high impact velocity. Varas et al. [25] analysed the high velocity impact of steel cylinders on thin carbon/epoxy woven laminates. The inter-lamina failure prediction was achieved by means of the use of cohesive elements. Pernas-Sánchez et. al. [26] predicted the behaviour of unidirectional composite plates when impacted at high velocity by a steel sphere projectile. The residual velocity in case of penetration and the damaged area in the panel were the variables chosen to validate the results obtained in their proposed numerical methodology. Muslim et. al. [27] presented a numerical investigation of penetration and perforation behaviour of FRP composite plates under impact. Xin and Wen [28] studied the impact behaviour of composite plate by experimental impact test and results were validated with theoretical model in terms of ballistic limit and residual velocity.

Aerospace industries have been seeking ways to restore sufficient strength to the damaged composite structures to ensure continued safe operation by repair the damage. There are many parameters that affect engineering decisions concerning which type of repair used, such as aerodynamics, residual strength, the strength restoration requirement and time. Therefore, a wide variety of bond patches have been designed over the years. Examples include the overlap joint, the scarf, and the stepped-lap which is presented by [29]. Megueni and Lousdad [30] found that strength restoration up to $80 \%$ of the ultimate allowable amount is sufficient for 
most repair geometries by change of the joints geometric. Several studies have been published regarding composite repairs and the development of bond technologies which have led to bonded patches becoming more structurally efficient, which minimises damage to the structure which some of these studies were conducted on repaired aircraft structures [31-33].

Stepped-lap repairs are the preferred methods of repair when there is a requirement for highstrength recovery or a flush surface is needed to satisfy the aerodynamic requirements of a damaged composite aircraft structure.

There are different studies investigating the effect of adhesively bonded stepped-lap joints on the strength of joint [34-37]. Ichikawa et. al. [38] studied the behaviour of a stepped-lap joint subjected to tensile loading by experimental and numerical finite element analysis. This study presented the edge of the adhesive which contains the highest value of the maximum principal stress. In the latest study, Aknipor [39] presented the behaviours of single lap joint, one step lap joint and three step lap joint by using experimental and numerical methods. It was observed that the three-step lap produces the lowest stress concentration at the edges of the bond line compared with one-step lap and single lap joint. Hart-Smith [40] performed an analytical models to investigate stepped-lap and scarf joints which considered adherend stiffness. Bendmra [41] studied the effect of joint parameters on stresses in stepped-lap and scarf repairs. In their work numerical models of stepped-lap and scarf joints compared the stresses for different joint configurations such as overply lap length, stacking sequence and overply layup.

One of the main objectives of this study is to provide further understanding of the behaviour of CFRPs under high velocity impact by using experimental and development of finite element models that can predict the nonlinear mechanical behaviour of repaired CFRPs composites. The change of kinetic energy and damage formulation were used to compare the simulation results with the related experimental results. 


\section{Experimental Studies}

The high velocity impact test rig was used to test composite panels subjected to various ranges of impact velocities. The modular design gives the gas gun the advantage of allowing easy repair, replacement, trouble-shooting or change of components without affecting other parts of the product. The gas gun test rig was designed employing a process of problem definition, team assembly, concept development, final concept review, prototype development and testing. The gas gun test rig, shown in Figure 1, utilises a variety of systems, including the gas system, support system and the velocity measurement system. This gas gun was single-stage, consisting of a pressure chamber and a nitrogen gas was used to launch it. The projectile velocity was measured using foil-screens and a digital oscilloscope was used to record the times of foil-screens perforation.
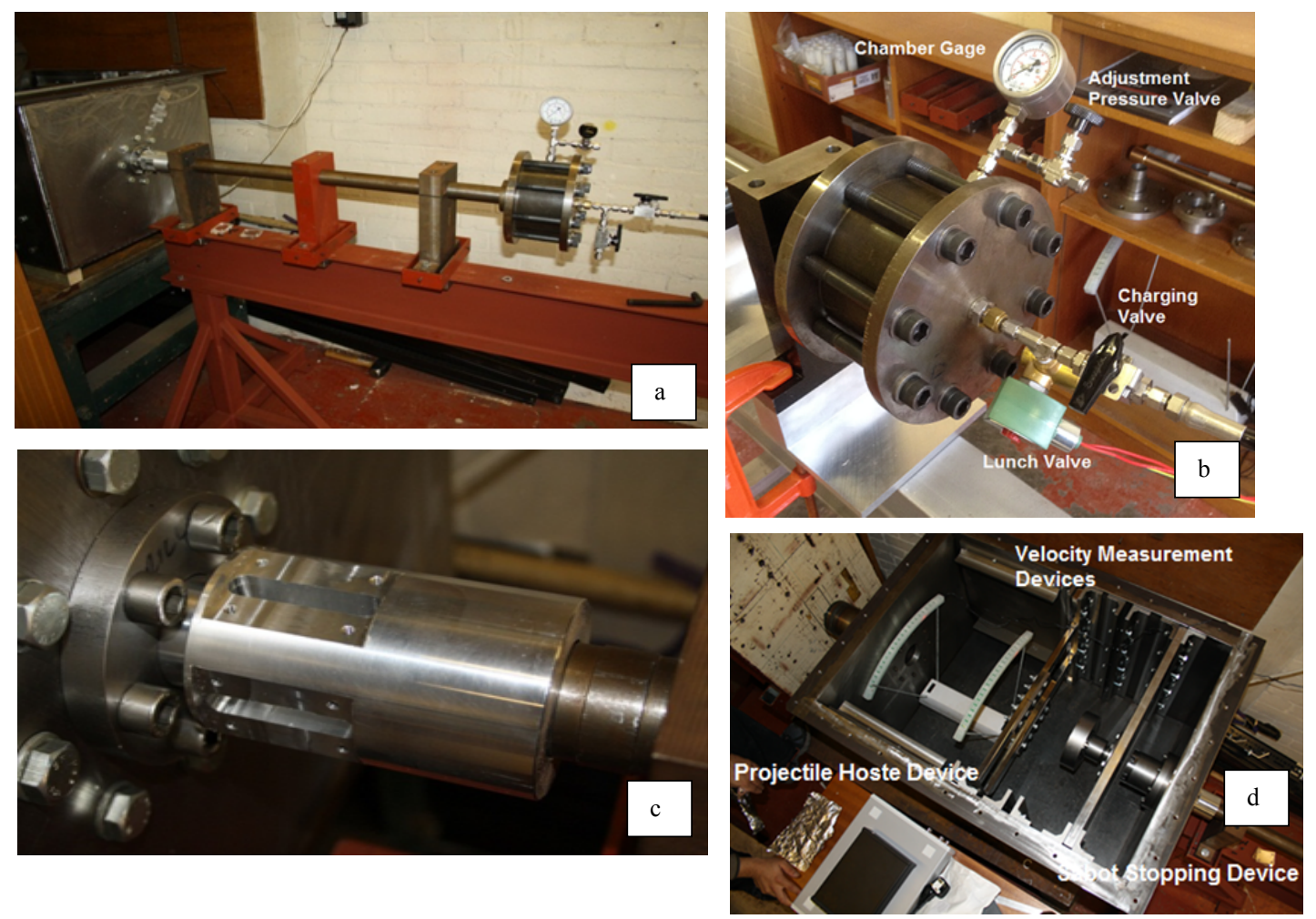

Fig. 1. a) gas gun test rig, b) gauge and valves in gun system, c) gas release device and d) impact chamber box.

Our experimental results were set to validate finite-element models and also to determine the failure characteristics, such as residual velocities and size of damage zone. The woven composite panel was made of Hexcel G0926 Carbon Fabric 5 harness 6K, Areal Wt 370 gsm. 
The resin of Hexcel RTM 6 was used and cured for 1 hour 40 minutes at $180 \mathrm{C}^{\circ}$ and at a pressure of 100 psi with average thickness $0.375 \mathrm{~mm}$.

These panels were comprised of 7 and 11 layers, using the following stacking sequence: $[(0 / 90) /( \pm 45) /(0 / 90) /( \pm 45) /(0 / 90) /( \pm 45) /(0 / 90) /( \pm 45) /(0 / 90) /( \pm 45) /(0 / 90)] \quad$ and $[( \pm 45) /(0 / 90) /(0 / 90) /( \pm 45) /(0 / 90) /(0 / 90) /( \pm 45)]$ and also 16 layers (Hazell, et. al., 2008) respectively. Dimension of specimens was $150 \times 150 \mathrm{~mm}^{2}$ with $4.125 \mathrm{~mm}$ and $2.625 \mathrm{~mm}$ in thickness, respectively. All composite specimens were secured into the support frame by clamping the top and bottom edges and leaving the side edges free (Figure 2).

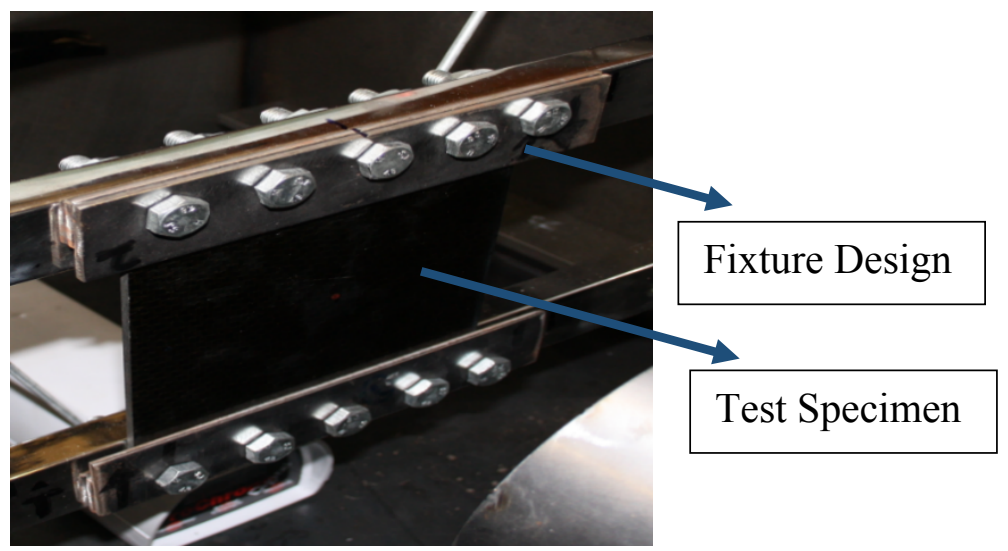

Fig. 2. Boundary conditions of the support frame.

The spherical projectile was used $(11.97 \pm 0.01 \mathrm{~mm})$, with a mass of $7.165 \mathrm{e}-6 \pm 1 \mathrm{e}-9$ Ton, and it was constructed from a fully annealed stainless steel (SS304) with an ultimate tensile strength of $675 \mathrm{MPa}$ and a Yield strength of $450 \mathrm{MPa}$.

Figures 3(a) and 3(b) show the failure behaviour of the 11 layered CFRP composite panel subjected to impact energy of $141 \mathrm{~J}(200 \mathrm{~m} / \mathrm{s})$ by the steel sphere projectile. Figure 3(a) shows a damaged area with a diameter of about $24 \mathrm{~mm}$ on the rear surface of the panel. Figure $3(\mathrm{~b})$ shows the front surface of the damaged panel, where the diameter of the damaged area is estimated about $15 \mathrm{~mm}$. These Figures clearly show that the damaged area changed significantly with the projectile velocity through the composite panel, with the damaged area on the front being smaller than the damaged area at the rear surface (Hazell, et. al., 2008), where a petalling or plug formation was apparent. 


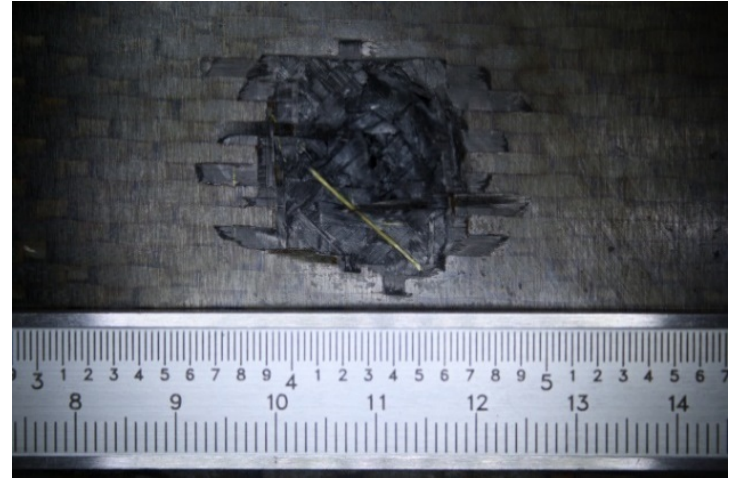

a

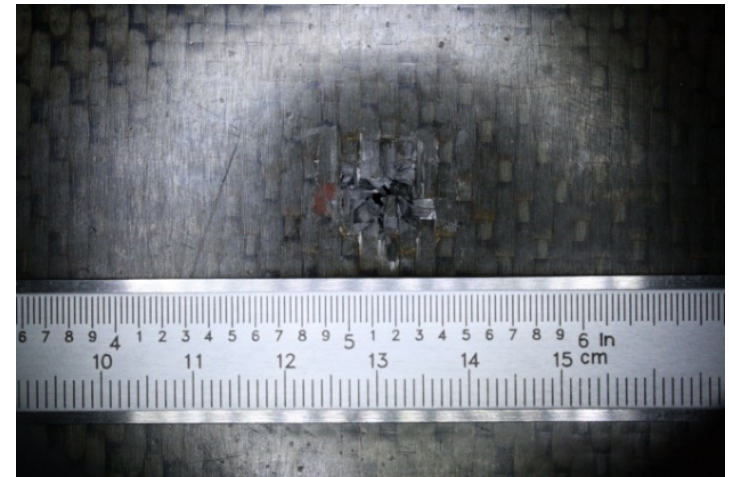

$\mathrm{b}$

Fig. 3. Impact failure of 11 layered CFRP woven compost panel impacted at $141 \mathrm{~J}$ $(200 \mathrm{~m} / \mathrm{s})$ : (a) rear surface and (b) front surface.

When the projectile velocity was less than $200 \mathrm{~m} / \mathrm{s}$, the failure (penetration) mechanism exhibited petalling (Figure 4), and when the velocity exceeded $200 \mathrm{~m} / \mathrm{s}$, the failure mechanism appeared as a plug formation.

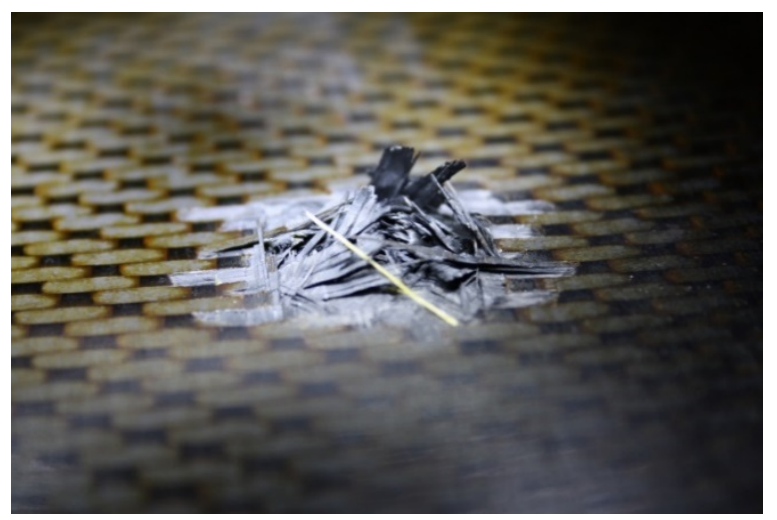

Fig. 4. Petalling formation failure of 11 layered CFRP woven compost panel impacted at $141 \mathrm{~J}(200 \mathrm{~m} / \mathrm{s})$.

Fig. 5 presents a micrograph of the impact failure of the 7 layered CFRP woven composite panel impacted at $141 \mathrm{~J}(200 \mathrm{~m} / \mathrm{s})$. This image shows the plies relaxing and closing up after impact by a steel sphere projectile. The tensile and compressive failure in petalling formation can be clearly observed. 


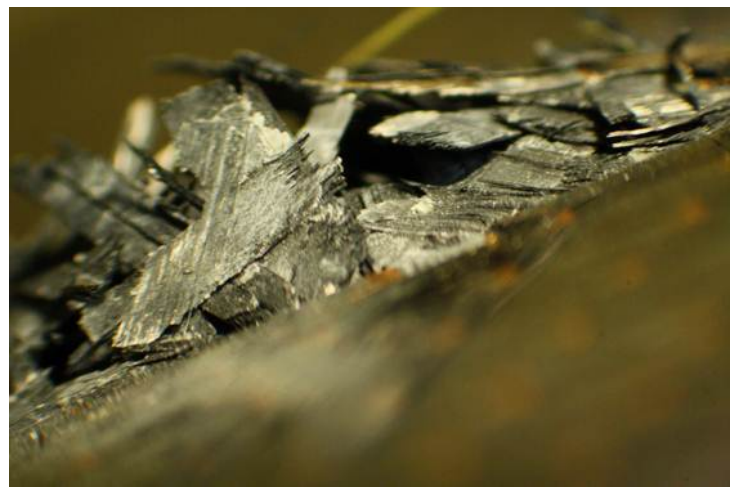

Fig. 5. Micrograph of impact failure of 7 layered CFRP woven compost panel impacted at $141 \mathrm{~J}(200 \mathrm{~m} / \mathrm{s})$.

\section{Numerical Impact Modelling}

The numerical analysis process of impact and penetration of CFRP specimen was performed to model the high velocity impact of composite panel. The spherical steel projectile was modelled using *MAT_ELASTIC_PLASTIC_HYDRO, as no significant deformation of the projectile was observed during the experimental test. The projectile is assumed to be ELASTIC PLASTIC HYDRO compared to the composite due to the difference of mass and stiffness, and because the modulus of the projectile is large compared to the through-thickness modulus of the composite. The projectile was spherical $(11.97 \pm 0.01 \mathrm{~mm})$ and constructed from a fully annealed stainless steel with a mass of $7.165 \mathrm{e}-6 \pm 1 \mathrm{e}-9$ Ton. This approximation reduced computational time and was very cost efficient. A four-node Belytschko-Tsay element with one through-thickness integration point was used for the projectile. The steel sphere projectile was meshed with 1023 elements and 1240 nodes and assigned the initial velocity.

The 4.124-mm thick CFRP panel was made from 11 plies and the $2.625 \mathrm{~mm}$ thick CFRP panel was made from 7 plies, each side with a length of $100 \mathrm{~mm}$. The CFRP panel was meshed with 111393 elements and 121380 nodes (see Figure 6), whereby one solid element was used to represent the thickness of each individual ply. The steel sphere projectile was meshed with 1023 elements and 1240 nodes and assigned an initial velocity. The solid elements ( 8 node hexahedron element) used a single integration point $($ ELFORM $=1)$ due to its computational efficiency over fully integrated elements. In addition, symmetry planes were defined to reduce computational time. Since it is a localised impact, the mesh of the plate under the projectile was much finer than other parts of the plane. Simply supported boundary conditions were 
applied along the edges of the plane, which is fixed in all directions. The above program takes about 15 hours of run time due to the size of mesh and time step.

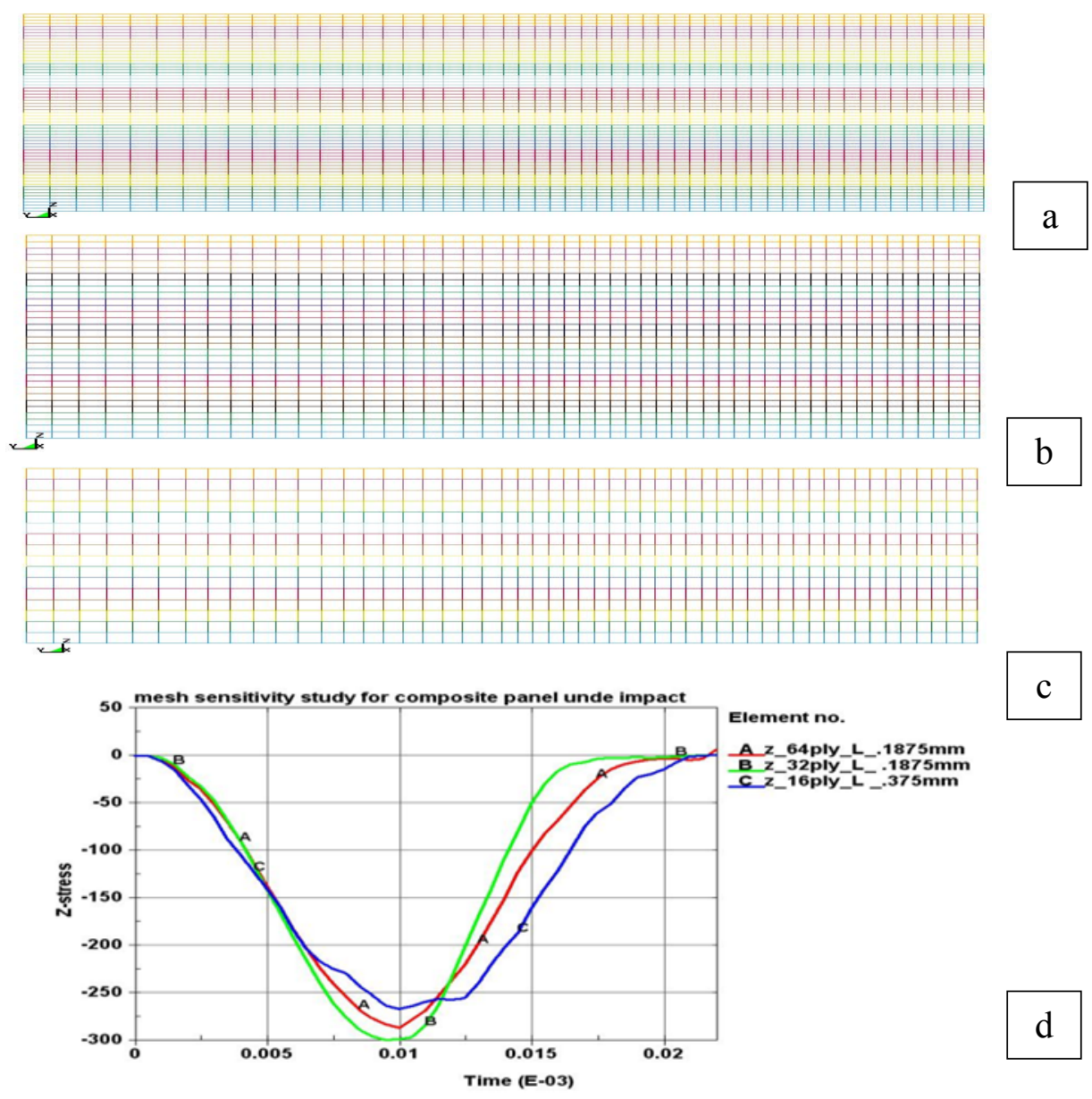

Fig. 6. Stress (MPa) vs time (sec) curves of the composite panels for different mesh size. a) no. of element $=445572$, b) no. of element $=222786$, c) no. of element $=111393$ and d) mesh sensitivity analysis.

\subsection{Composite Panel Parameters}

After experimenting with numerous models, material model MAT_59 (MAT_COMPOSITE_ FAILURE_SOLID_MODEL) was chosen to model the target. In *MAT_59, twenty material parameters are required to enable the predictive modelling of impact damage on composite panel. The experimental data provided by Hazell [42] as initial baseline values for the composite were implemented and tuned to provide a better correlation against experimental results. For this study, the change in kinetic energy was deemed to be a useful parameter, as approximating this value would ensure a representative stiffness of the overall plate, not only during initial failure, but also incorporating the resulting change in stiffness/element deletion for subsequent ply failures (see Table 1). 
Table 1. Material parameters for CFRP laminates

\begin{tabular}{ccccccccc}
\hline $\mathbf{E}_{\mathbf{a}}$ & $\mathbf{E}_{\mathbf{b}}$ & $\mathbf{E}_{\mathbf{c}}$ & $\mathbf{G}_{\mathbf{a b}}$ & $\mathbf{G}_{\mathbf{b c}}$ & $\mathbf{G}_{\mathbf{c a}}$ & $\mathbf{v}_{\mathbf{b a}}$ & $\mathbf{v}_{\mathbf{b c}}$ & $\mathbf{v}_{\mathbf{c a}}$ \\
\hline $72.2 \mathrm{GPa}$ & $72.2 \mathrm{GPa}$ & $1.12 \mathrm{GPa}$ & $6 \mathrm{GPa}$ & $6 \mathrm{GPa}$ & $6 \mathrm{GPa}$ & 0.04 & 0.04 & $4 \mathrm{E}-4$ \\
\hline $\mathrm{XX}_{\mathrm{T}}$ & $\mathrm{YY}_{\mathrm{C}}$ & $\mathrm{S}_{\mathrm{BA}}$ & $\mathrm{XX}$ & $\mathrm{YY}_{\mathrm{T}}$ & $\mathrm{S}_{\mathrm{CB}}$ & $\mathrm{S}_{\mathrm{CA}}$ & $\mathrm{ZZ}_{\mathrm{T}}$ & $\mathrm{ZZ}$ \\
\hline $833 \mathrm{MPa}$ & $833 \mathrm{MPa}$ & $100 \mathrm{MPa}$ & $698 \mathrm{MPa}$ & $698 \mathrm{MPa}$ & $60 \mathrm{MPa}$ & $60 \mathrm{MPa}$ & $698 \mathrm{MPa}$ & $833 \mathrm{MPa}$ \\
\hline
\end{tabular}

\subsection{Impact Damage Simulation}

Simulations were performed for composite panels subjected to high velocity impact by spherical projectiles Figure 7. The range of projectile velocity is between $180-400 \mathrm{~ms}^{-1}$. When the projectile penetrates the panel, significant damage occurs, including delamination, compression through thickness failure, out-of-plane shear failure and in-plane tensile failure of the fibres located at the rear surface, where high tensile stresses develop. The results of this simulation show the capability of the methodology to capture the material failure mechanisms during penetration.

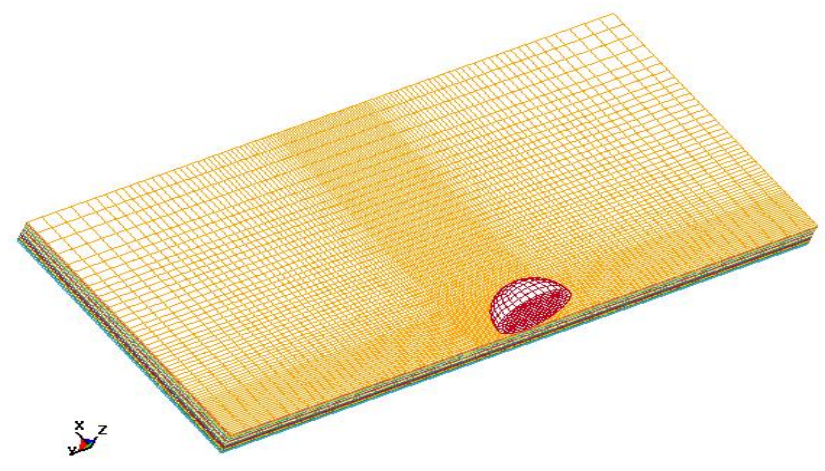

Fig. 7. Finite element model of plate and striker.

In the dynamic simulation, hourglass energy (HGE) modes represent non-physical, zero-energy modes of deformation that produce zero strain and stress. An accurate simulation requires a very small hourglass, such as $10 \%$ of the peak of the internal energy (IE). High amounts of hourglass energy can cause modelling instability. For this study, mesh refinement and the HGE coefficient type $4(\mathrm{QM}=0.1)$, which provides a stiffness-based control, thereby minimizing distortion of the elements, was used to reduce the hourglass energy. The choice of the time step is critical in a dynamic analysis because a small time step can make the computation inefficient and large time steps may produce unstable simulations. 


\section{Verification of the Model}

The numerical model were correlated with experimental data reported by [42] and also our experimental results. The material type and size as well as the condition used in computational model were the same as those reported in the experimental studies. When the projectile penetrates the panel many damages took place such as delamination, compressive through thickness failure, out-of-plane shear failure and in-plane tensile failure of the fibres located at back surface where high tensile stresses develop. The results of this simulation showed the capability of the methodology to capture the real material failure mechanisms including the penetration. Delamination damage and progress damage were not predicted in this simulations because the limitation of material model.

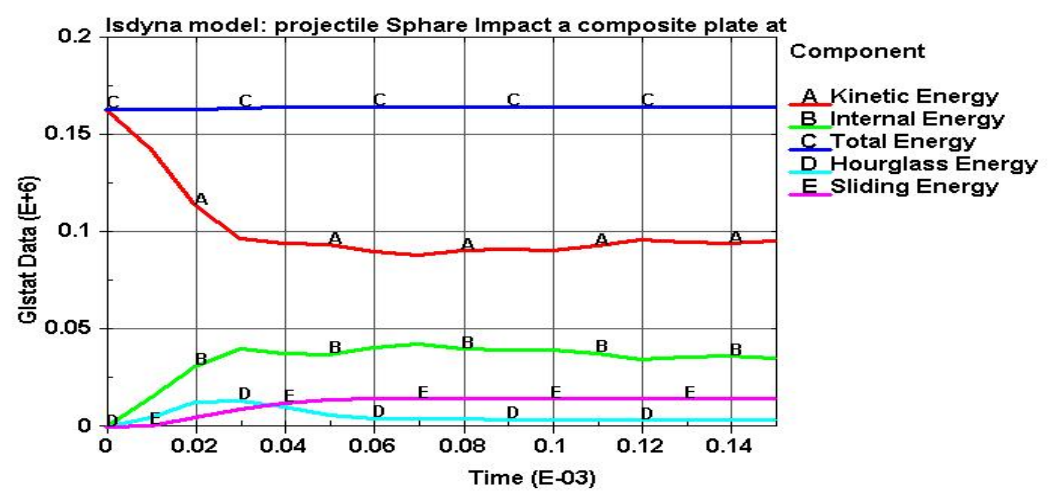

Fig. 8. Simulation results showing the global energy (J) versus time(s) for the 16 layer laminates.

The kinetic energy of the projectile is transferred to the target. Therefore, the kinetic energy of projectile will be reduced and the internal energy of the system will be increased as shown in Figure 8. Damage growth can be attributed to the combination of fibre failure modes. For example, the fibre crush provides high resistance to penetration which has been shown in Figure 8 as decrease of kinetic energy from 0 to 0.03 . Figure 9 shows the comparison between experimental and simulation results for penetration processes in a specimen with initial velocity $354 \mathrm{e}+3 \mathrm{~mm} / \mathrm{s}$. Once the projectile impacts the target the fracture initiates immediately in the composite panel. These fractures occur within $2 \mu$ s and the projectile reaches the end of the target at $30 \mu \mathrm{s}$. The plug was formed and pushed in front of the projectile at $60 \mu$ s and the specimen completes the penetration at $70 \mu \mathrm{s}$. 

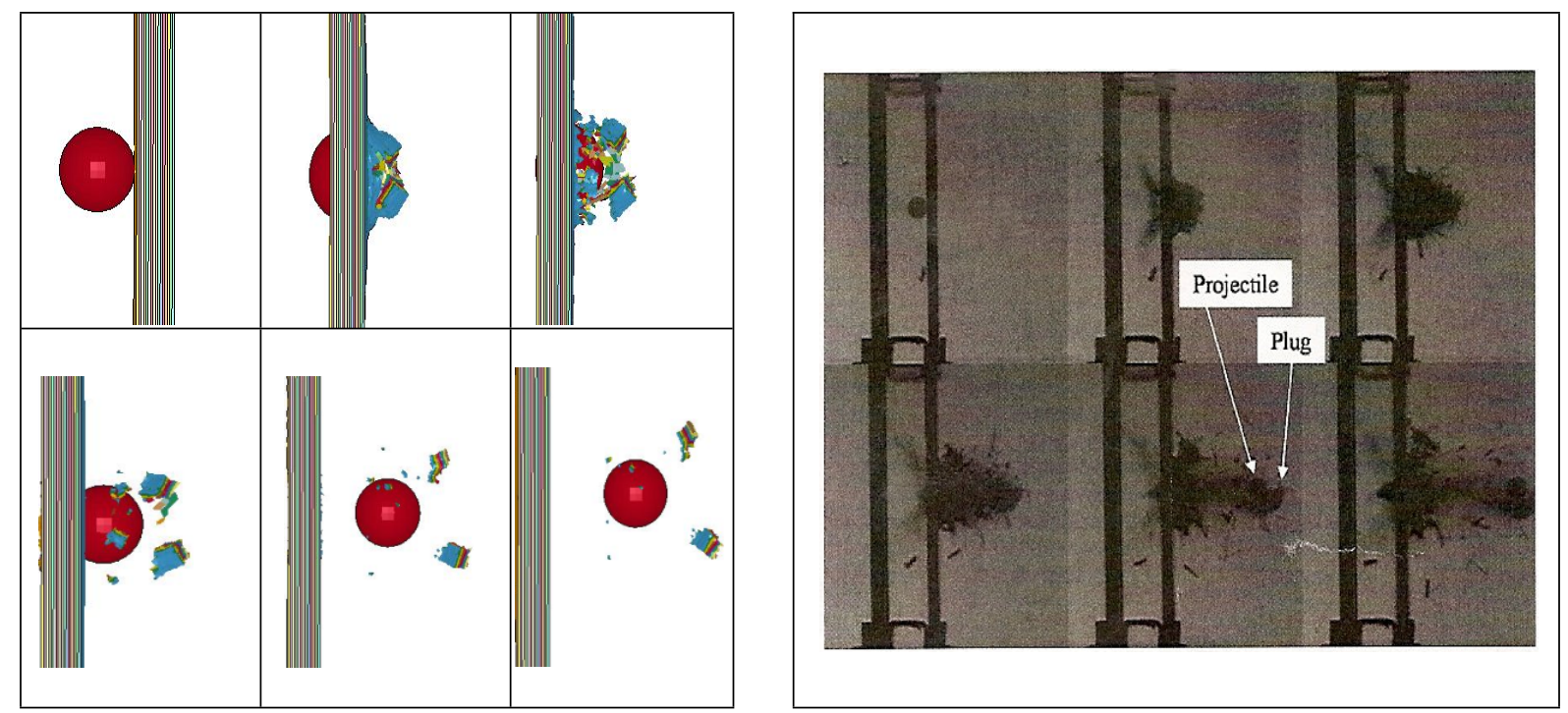

Fig. 9. Penetrations of CFRP laminate panel (a) simulation (b) experiment [42].

Figure 10 shows the variation of the change in kinetic energy versus the initial impact kinetic energy. This figure also compares the experimental and the simulation results for the change in kinetic energy. It can be seen that the results significantly matched in all simulated cases and the absorbed energy was adequately captured. The residual kinetic energy is $5.0 \%$ larger than experimental data. This slight difference in the residual kinetic energy of the projectile can be attributed to neglect of the frictional energy of eroding elements surrounding the projectile during penetration, and/or the mesh size may not be refined enough for the penetration.

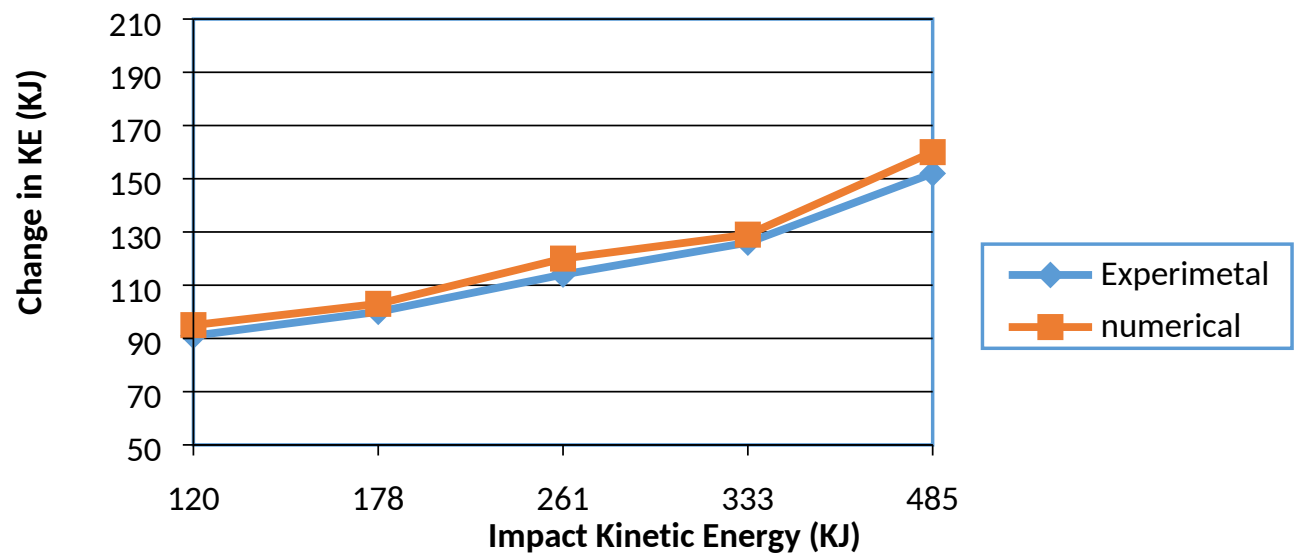

Fig. 10. The change in kinetic energy of the projectile against the initial impact energy between $120 \mathrm{~kJ}(\mathrm{v}=183 \mathrm{~m} / \mathrm{s})$ to $485 \mathrm{~kJ}(\mathrm{v}=368 \mathrm{~m} / \mathrm{s})$.

The penetration mechanism of the projectile had a "plugging-type" (shear) failure. In this case, transverse shear strength is the predominant strength parameters. The hole that was formed after impact was conical shaped as shown in Figure 11 and cones that were formed varied in size with the kinetic energy of the projectile. 


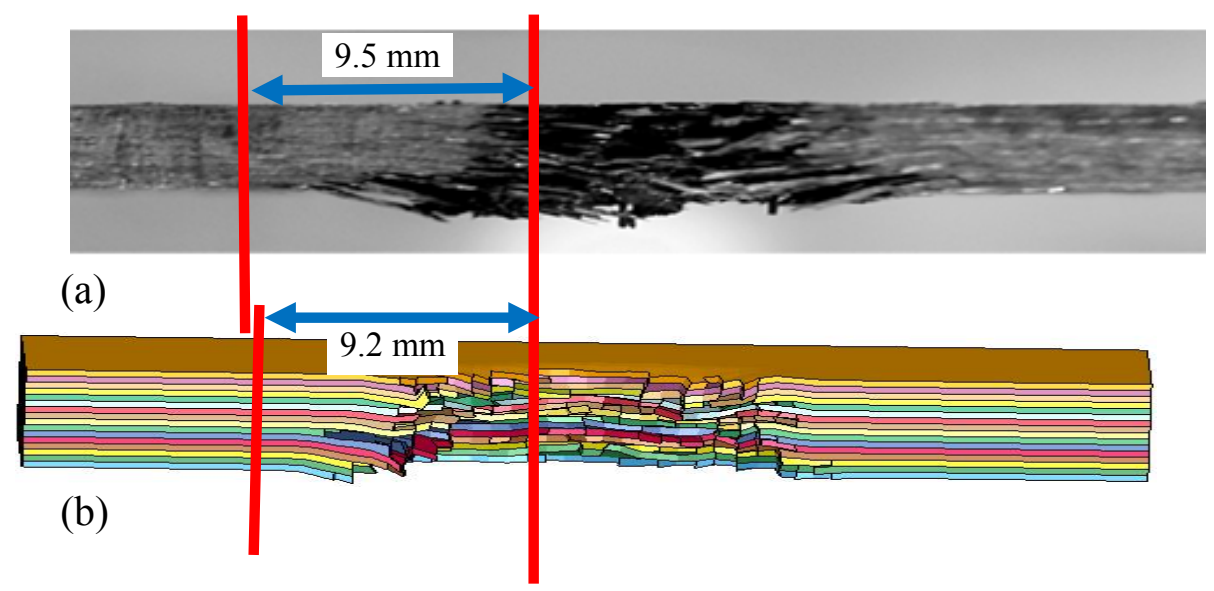

Fig. 11. The conical shaped hole formed on $6 \mathrm{~mm}$ CFRP laminate after impact by a steel sphere projectile velocity of 305m/s: (a) experimental results [42]; (b) numerical results.

On impact, different types of failure were exhibited, such as delamination and fibre breakage. The petalling failure was created by the following process: the projectile pushed the plies, then the plies relaxed, thus nearly closing up the penetration hole. During the impact event, some fragments were produced as part of plug formation. The transfer of projectile kinetic energy to target CFRP composite panels is dependent on the thickness of the target. Figure 12 presents a comparison between two woven CFRP composite panels of two different thicknesses $(4.125 \mathrm{~mm}$ and $2.625 \mathrm{~mm})$ with different layering (11 layers and 7 layers) in both experimental and simulation methods. The residual kinetic energy for both methods used in this study showed a slight difference of about 5\% between simulation and experimental results for the 7 layer versus the 11 layer panels, as shown in Figure 12. This difference in the residual kinetic energy of the projectile is due to two possible reasons: the frictional energy of eroding elements surrounding the projectile during penetration which is neglected; and/or the mesh size may not be refined enough for the penetration. 


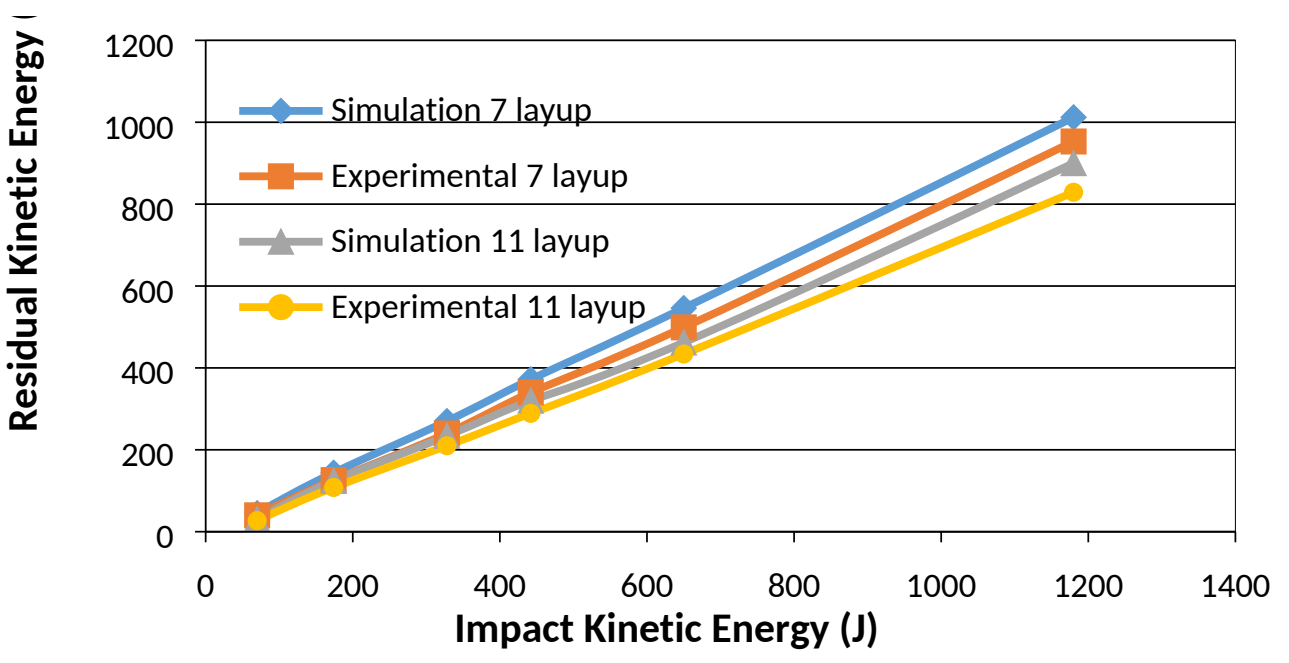

Fig. 12. The residual kinetic energy of the projectile against the initial impact kinetic energy for two different thickness composite panels: $2.625 \mathrm{~mm}$ (7 layers) and 4.125 mm (11 layers).

This comparison shows the residual kinetic energy for the 7 layered CFRP composite panel is higher than other panel (11 layers), which is in line with the expectations. The difference indicates that the 11 layered CFRP composite panel provided better penetration resistance than the thinner with 7 layered panel. This behaviour of CFRP composite panels under high velocity impact shows the effect of the thickness of panels on residual kinetic energy. The residual kinetic energy of a projectile increases with increasing initial impact energy, which means the kinetic energy is absorbed by an increase in composite panel layers.

\section{Numerical Repair Model}

In this section a numerical model is developed to predict the behaviour of a repaired CFRP composite panel under static compressive loading. Thus, the main objective of this section was to create a general program that can be used to model the repaired composite panels. A simulation guideline for repair of impact damage on composite panels has been created in this research and includes many key factors as shown in Figure 13. 


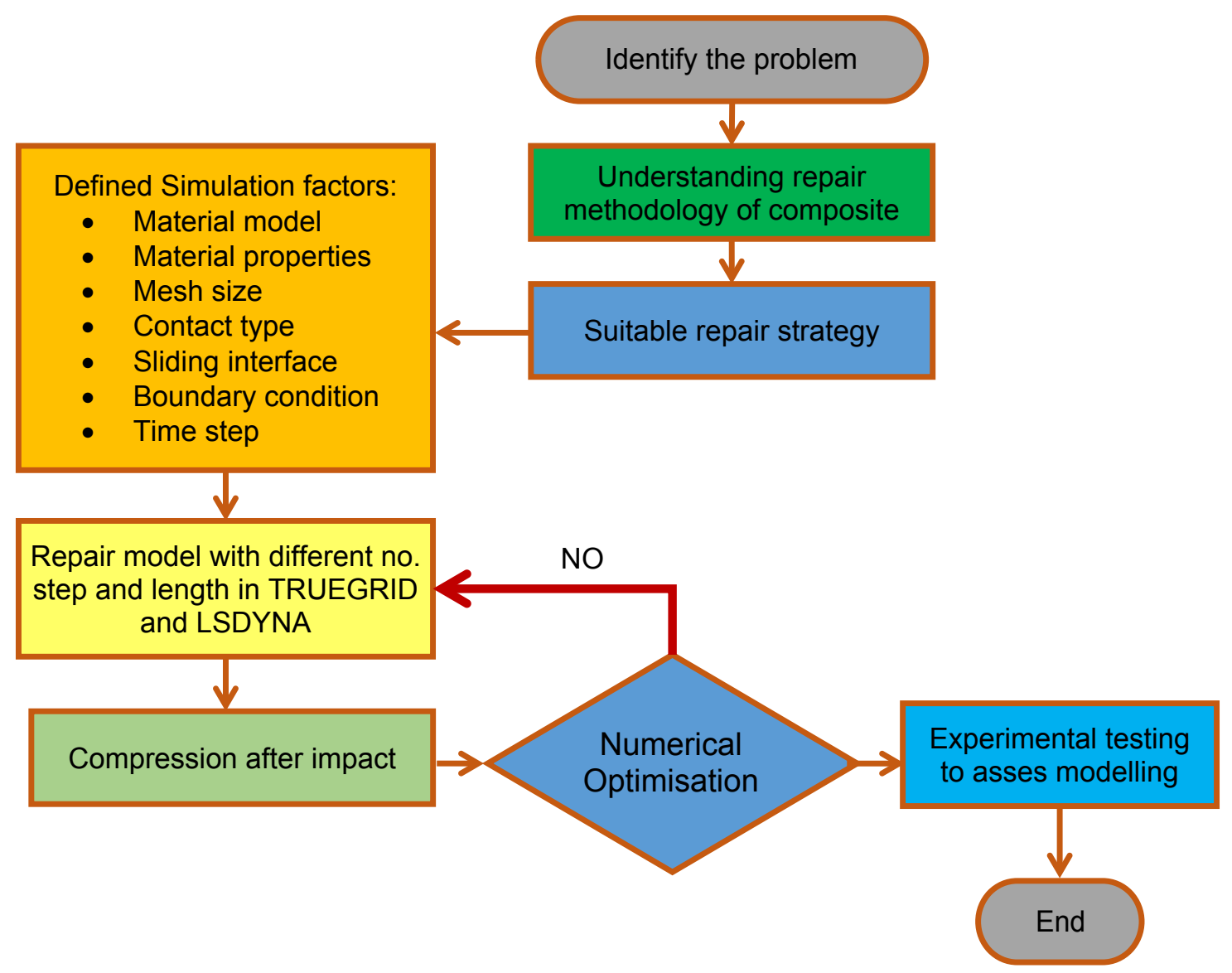

Fig. 13. The simulation guideline for repairing strategy of impact damage.

The modelling of the geometry of repaired CFRP composite panel was carried out via the TRUGRID program. The geometry includes three steps as outer repaired area (parent part); hole area (joint part); and stepped area including the parent, joint, and adhesive parts.

The number of steps (n) can be defined as the number of horizontal length of steps (L) and radius (r) which are defined in Figure 14.

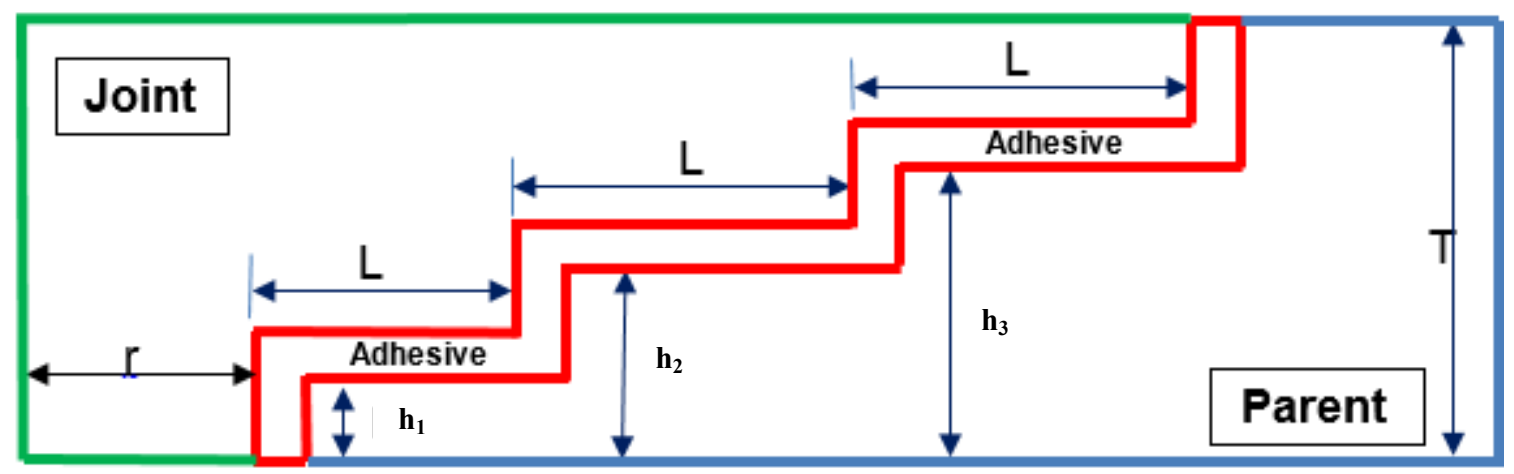

Fig. 14. Height and length of each step $(n=3)$. Total repaired composite panel thickness $=$ $4.125 \mathrm{~mm}$, length $($ Tall $)=150 \mathrm{~mm}$ and adhesive thickness $(D)=0.375 \mathrm{~mm} . \mathrm{h}_{1}=1.125 \mathrm{~mm}$, $\mathrm{h}_{2}=2.25 \mathrm{~mm}$ and $\mathrm{h}_{3}=3.375 \mathrm{~mm}$. 

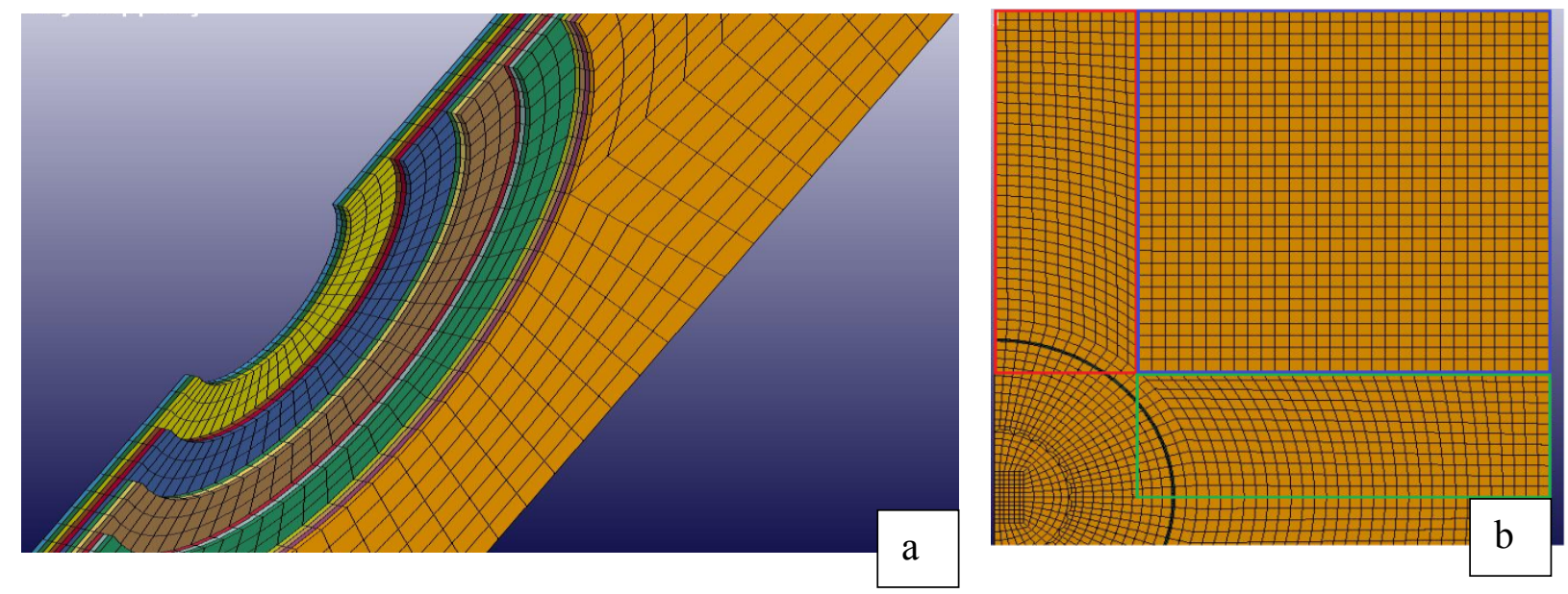

Fig. 15. Complete FE model for the parent part a) side view \& b) top view.

The step area was modelled using the sphere projection method and the transition block boundary interface technique (reduction element number), which reduced the number of elements to minimise the time cost. Figure 16 shows the quarter step area, including joint area, adhesive area and parent area, which is presented via the transition technique.

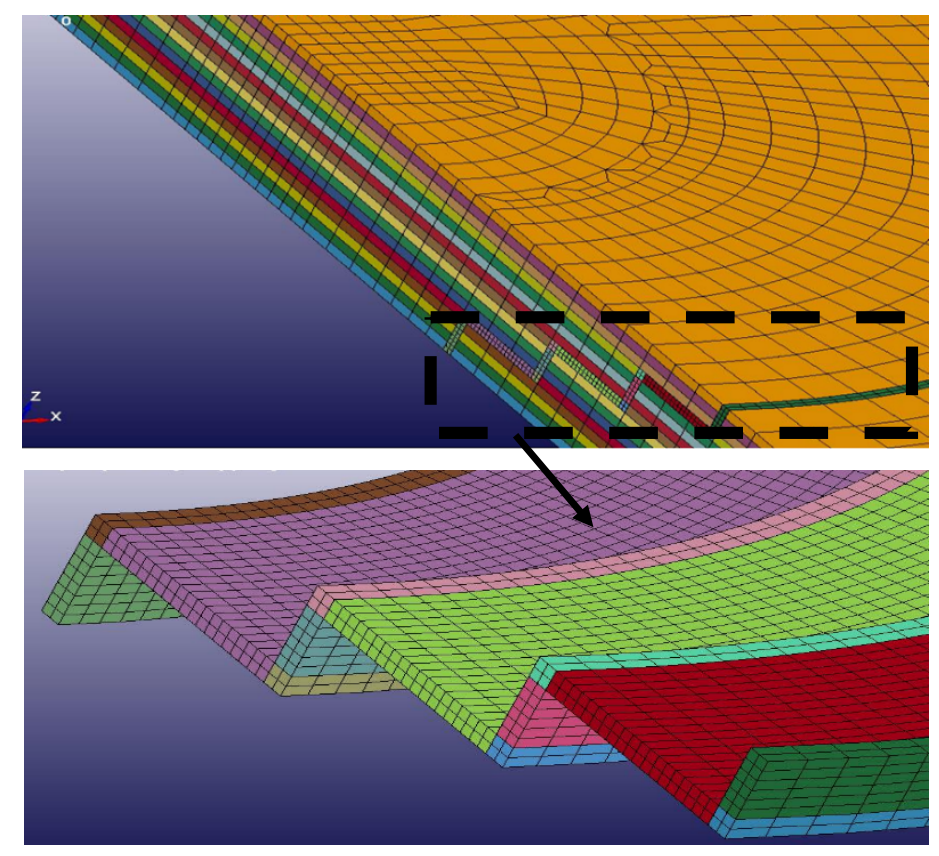

Fig. 16. Step area including joint area, adhesive area and parent area.

This model uses two methods to define the contact algorithm, the first method is tied contact, which is more realistic than other contact methods and applied between adhesive parts and other parts (joint and parent) due to differences in the mesh size. The second method used 
normal contact (normal merge) between all parts in the joint and parent area. Element size of both sides of the contact area in the joint and parent area was similar to avoid any errors in the methodology.

\section{Compression after Impact}

The developed numerical procedure is used to investigate the behaviour of undamaged, damaged, and repaired composite panels during the compression after impact (CAI) tests. This procedure is performed to assess the residual strength properties of composite panels which have been impacted and repaired.

Due to the symmetry assumption the panel was modelled as half specimen. The boundary condition of the model was clamped at one end and the load was applied to another end as shown in Figure 17.

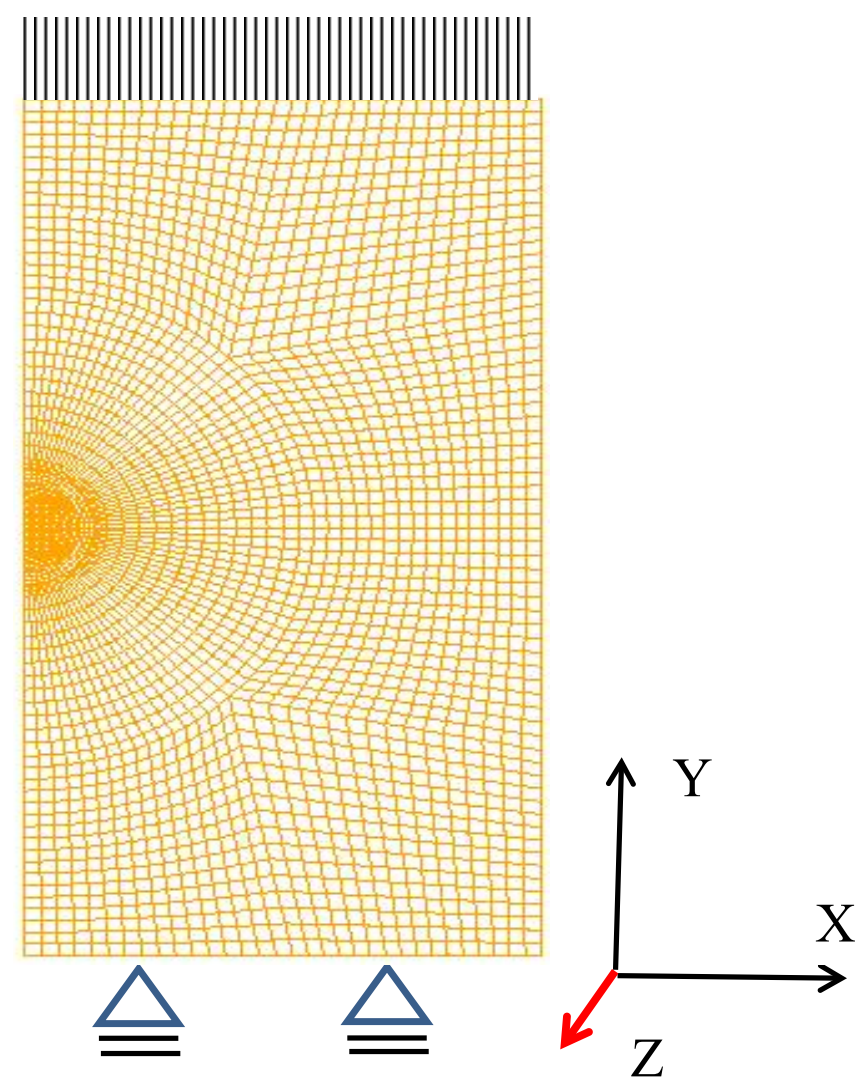

Fig. 17. Boundary conditions of the repaired CFRP composite panel.

The Compression after impact simulations are performed with LSDYNA using an explicit solver. The 8-node solid elements were used in this model. The boundary condition and force 
were applied in this model in y-direction from one side and clamp from other side. To reduce time cost the velocity of applied force increased to $300 \mathrm{~mm} / \mathrm{sec}$.

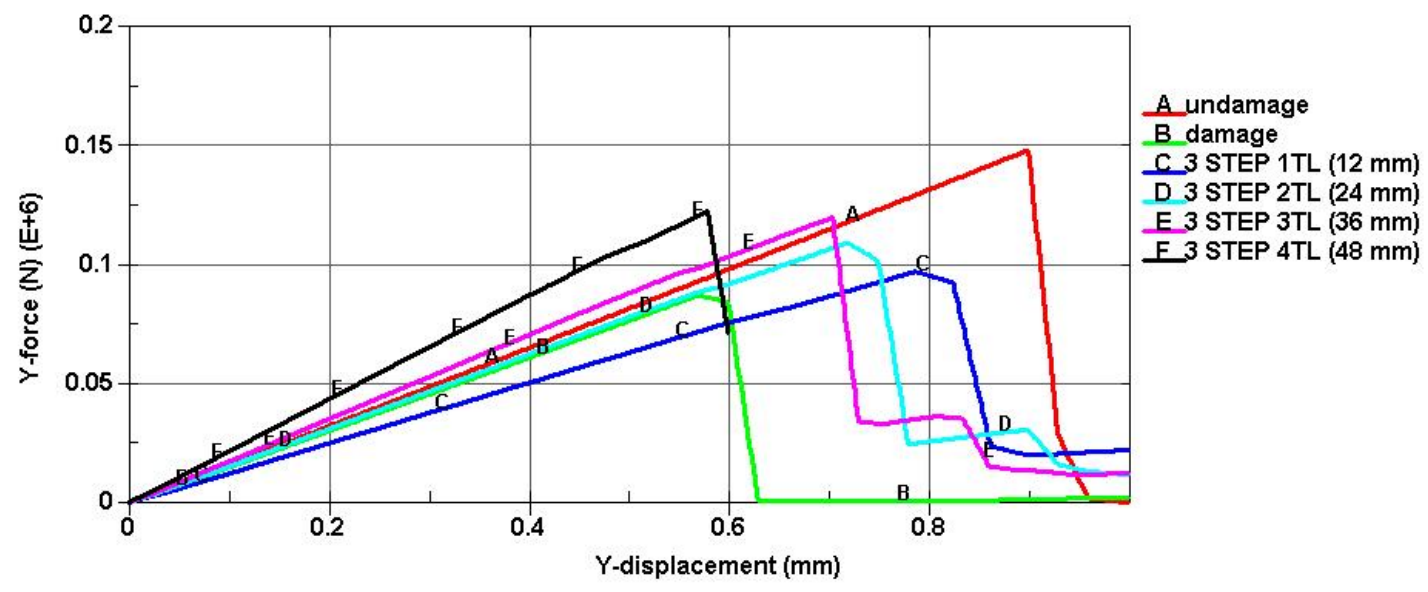

Fig. 18. Failure load versus displacement for various stepped lap joint.

Figure 18 shows the failure load of stepped joints (three steps) for various overlap lengths (TL). The failure loads increase when total overlap length increases from $12 \mathrm{~mm}$ to $48 \mathrm{~mm}$ as shown in Figure 18. The undamaged panel failed at an average of $450(\mathrm{MPa})$ and damaged panel failed at a significantly smaller compression load compared to the panel, with an average reduction in peak load of $52 \%$.

As seen in Figure 18 the stepped lap joint with the three different overlap lengths configuration was able to restore the compression failure load of the damaged panel to $82 \%$ of that for the undamaged panel. The compression failure load increases by $14 \%$ when the overlap length increases from $12 \mathrm{~mm}$ to $36 \mathrm{~mm}$. However, further increases overlap length to $48 \mathrm{~mm}$ had no significant effect. Therefore it has been defined the optimal overlap length $(36 \mathrm{~mm})$ in the three stepped lap joint level. A typical compressive strength versus displacement is shown in Figure 19. It is apparent that the compressive strength of damage panel is much less than undamaged panel by $55 \%$. The compressive strength for repaired panel increase by $11 \%$ when the overlap length increase from $12 \mathrm{~mm}$ to $24 \mathrm{~mm}$. Then the compressive strength significantly decreased by $17 \%$ when the overlap length increases to $36 \mathrm{~mm}$ and $48 \mathrm{~mm}$. The compressive strength of the repaired panel decreased slightly as a result of local buckling. 


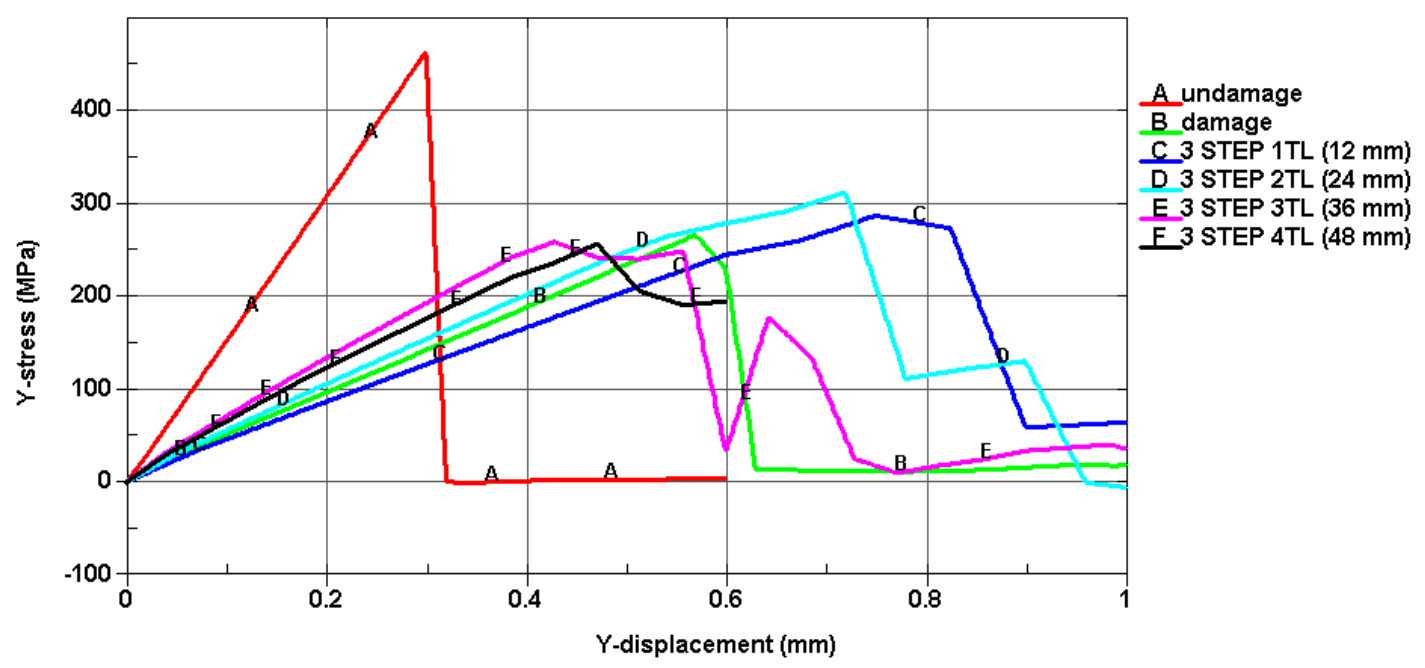

Fig. 19. Compressive strength versus displacement for stepped lap joint with different overlap length.

Figure 20 shows the stress (z-direction) along the path line of mid-surface of various stepped lap joint. The peak stress at the end step explains why failure always initiates at the end step of the bonded region.

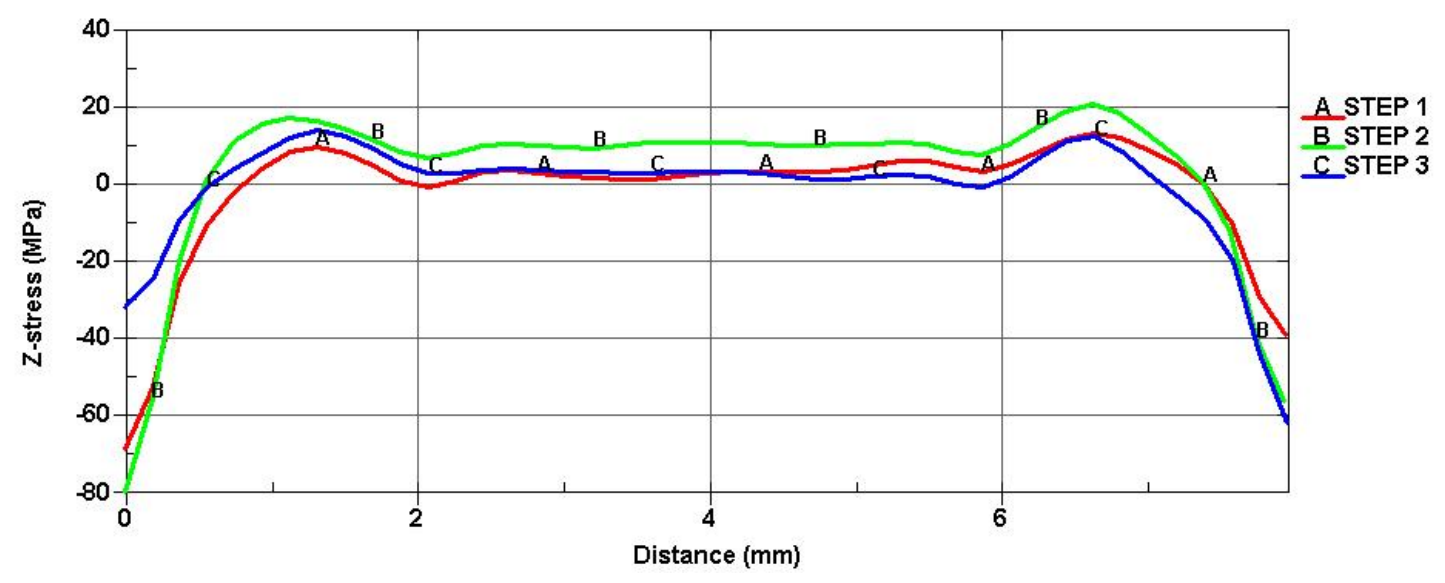

Fig. 20. Stress along the path line of mid-surface of the stepped lap joint.

Two main factors which have been studied in a repaired geometry were number of steps and overlap length. Figure 21 shows the overall stress level which increases with the increase of overlap length. 


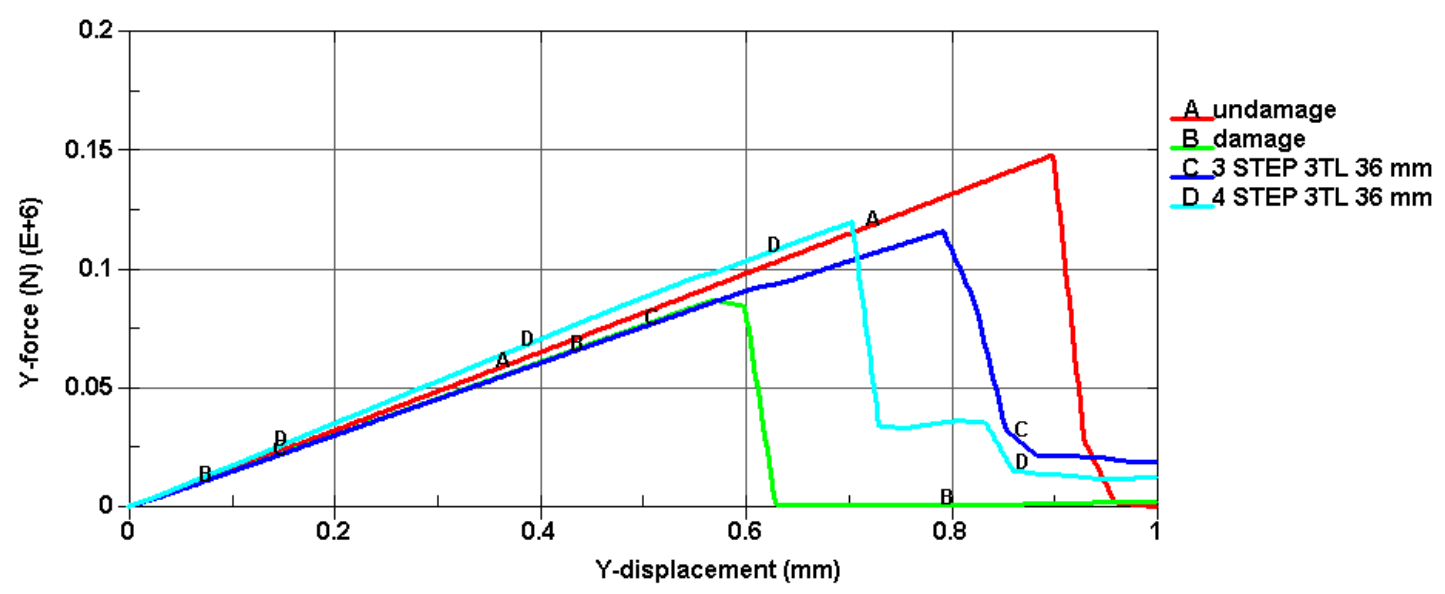

Fig. 21. Stress along the path line of mid-surface of the stepped lap joint.

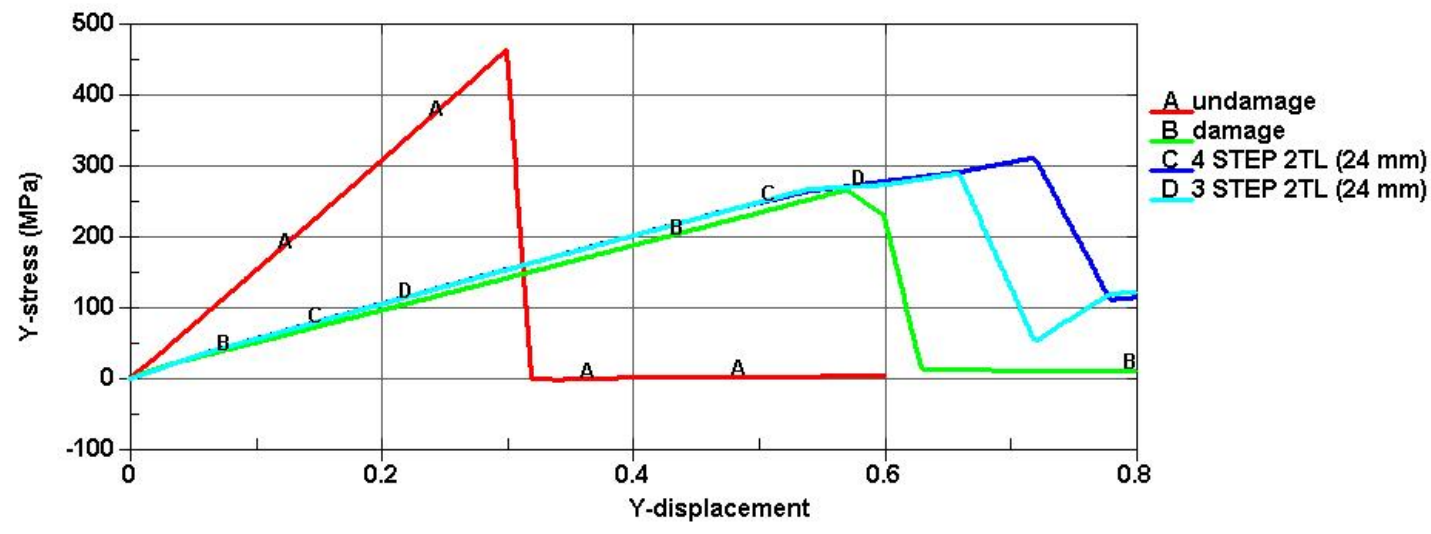

Fig. 22. Comparison between undamaged and damaged model with different steps.

Considering the results presented in Figure 22 in terms of repaired methods (number of step), for most of the joint geometries, the maximum joint failure load are found in the stepped lap joints with three steps by $82 \%$ from undamaged panel. When the number steps is three steps the failure load increased by $12.5 \%$ from fourth step. The compressive strength for two different repair design methods (number of steps) are 280, and $310(\mathrm{MPa})$. Typical loaddisplacement curves of stepped lap joints (four steps) under compression with different overlap length are shown in Figure 23.

\section{Conclusion}

Damage in CFRP composite laminate subjected to high velocity impact was investigated by numerical simulation and experimental. The numerical prediction of kinetic energy and shape of damaged area of CFRP laminates was in close agreement with the experimental result. The results show the simulation programme can be utilised in the next step, which is to simulate 
the repaired (damaged) CFRP woven compost panel and then applying compression after the impact test for undamaged, damaged and repaired CFRP woven compost panels.

\section{References}

[1] Aviation Research and Analysis Report AAR-2007-021, Australian Transport Safety Bureau, (2007).

[2] Abrate, S. Impact on composite structures, Cambridge University Press, Cambridge (1998).

[3] Bland, P. W. and Dear, J. P. Observations on the impact behaviour of carbon-fibre reinforced polymers for the qualitative validation of models. Composites Part A: Applied Science and Manufacturing, 32(2001) 1217-1227.

[4] Olsson, R. Mass criterion for wave controlled impact response of composite plates. Composites Part A: Applied Science and Manufacturing, 31(2000) 879-887.

[5] Cantwell, W. J. and Morton, J. Comparison of the low and high velocity impact response of CFRP. Composites, 20(1989) 545-551.

[6] Zukas, J. A. High velocity impact dynamics, Wiley, New York ; Chichester. (1990),

[7] Abrate, S. Impact on laminated composite materials: recent advances. Applied Mechanics Review. 47(1994), 517-544.

[8] Abrate, S. Impact on laminated composite materials. Applied Mechanics Review. 44(1991) 155-190.

[9] Chen, J. K., Allahdadi, F. A. and Carney, T. C. High-velocity impact of graphite/epoxy composite laminates. Composites Science and Technology. 57(1997) 1369-1379.

[10] Sun CT, Potti V. A simple model to predict residual velocities of thick composite laminates subjected to high velocity impact. Int J Impact Eng 18(1996) 339-353.

[11] López-Puente J, Zaera R, Navarro C. The effect of low temperatures on the intermediate and high velocity impact response of CFRP. Composites: Part B 33(2002) 559-566.

[12] López-Puente J, Zaera R, Navarro C. High energy impact on woven laminates. J Phys IV 110(2003) 639-644.

[13] Hosur MV, Vaidya UK, Ulven C, Jeelani S. Performance of stitched/unstitched woven carbon/epoxy composites under high velocity impact loading. Compos Struct 64(2004) $455-566$.

[14] López-Puente J, Zaera R, Navarro C. An analytical model for high velocity impacts on thin CFRPs woven laminates. In J Solids Struct 44(2007) 2837-2851. 
[15] Garcia-Castillo SK, Sanchez-Saez S, López-Puente J, Barbero E, Navarro C. Impact behaviour of preloaded glass/polyester woven plates. Compos Sci Technol 69(2009) 711717.

[16] Varas D, Artero-Guerrero JA, Pernas-Sánchez J, López-Puente J. Analysis of high velocity impacts of steel cylinders on thin carbon/epoxy woven laminates. Compos Struct 95(2013) 623-629.

[17] Cantwell WJ, Morton J. An assessment of the impact performance of CFRP reinforced with high-strain carbon-fibers. Compos Sci Technol 25(1986) 133-148.

[18] Abrate S. Modeling of impacts on composite structures. Compos Struct 51(2001) 129138.

[19] Ambur, D. R., Jaunky, N., Lawson, R. E. and Knight, N. F. Numerical simulations for high-energy impact of thin plates. International Journal of Impact Engineering. 25(2001) 683-702.

[20] Fujii, K., Aoki, M., Kiuchi, N., Yasuda, E. and Tanabe, Y. Impact perforation behavior of CFRPs using high-velocity steel sphere. International Journal of Impact Engineering. 27(2002) 497-508.

[21] Tanabe, Y., Aoki, M., Fujii, K., Kasano, H. and Yasuda, E. Fracture behavior of CFRPs impacted by relatively high-velocity steel sphere. International Journal of Impact Engineering. 28(2003) 627-642.

[22] Hammond, R. I., Proud, W. G., Goldrein, H. T. and Field, J. E. High-resolution optical study of the impact of carbon-fibre reinforced polymers with different lay-ups. International Journal of Impact Engineering. 30(2004) 69-86.

[23] Chan, S., Fawaz, Z., Behdinan, K. and Amid, R. Ballistic limit prediction using a numerical model with progressive damage capability. Composite Structures, 77(2007) 466-474.

[24] López-Puente J, Zaera R, Navarro C. Experimental and numerical analysis of normal and oblique ballistic impacts on thin carbon/epoxy woven laminates. Composites: Part A 39(2008) 374-387.

[25] Varas D, Artero-Guerrero J.A, Pernas-Sánchez J, López-Puente J. Analysis of high velocity impacts of steel cylinders on thin carbon/epoxy woven laminates. Composite Structures 95(2013) 623-629.

[26] Pernas-Sánchez J, Artero-Guerrero J.A, Zahr Viñuela J, Varas D, López Puente J. Numerical analysis of high velocity impacts on unidirectional laminates. Composite Structures 107(2014) 629-634 
[27] Muslim A, Anupam C. Impact behavior of FRP composite plate under low to hyper velocity impact. Composites Part B 95(2016) 462-474

[28] Xin S, Wen H. A progressive damage model for fibre reinforced plastic composites subjected to impact loading. Int J impact Eng 75(2015) 40-52.

[29] Gunnion, A. J. and Herszberg, I. Parametric study of scarf joints in composite structures. Composite Structures, 75 (2006), 364-376.

[30] Megueni, A. and Lousdad, A. Comparison of symmetrical double sided and stepped patches for repairing cracked metallic structures. Composite Structures, 85(2008), 91-94.

[31] Baker, A. (1997), "Joining and repair of aircraft composite structures", in UNITED STATES, New York: Marcel Dekker, Inc. (Materials Engineering. Vol. 11).

[32] Megueni, A. and Lousdad, A. Comparison of symmetrical double sided and stepped patches for repairing cracked metallic structures. Composite Structures. 85(2008) 91-94.

[33] Campilho, R. D. S. G., de Moura, M. F. S. F. and Domingues, J. J. M. S., "Numerical prediction on the tensile residual strength of repaired CFRP under different geometric changes", International Journal of Adhesion and Adhesives, 29(2009) 195-205.

[34] Kimiaeifar A, Lund E, Thomsen OT, Sorensen JD. Asymptotic Sampling for reliability analysis of adhesive bonded stepped lap composite joints. Eng Struct 49(2013) 655-663.

[35] Kim JH, Park BJ, Han YW. Investigating the flexural resistance of fibre reinforced cementitious composites under biaxial condition Compos Struct 66(2004) 69-75.

[36] Li D, Qing G, Liu Y. A layerwise/solid-element method for the composite stiffened laminated cylindrical shell structures. Compos Struct 93(2011) 1673-1682.

[37] Kim HS, Lee SJ, Lee DG. Development of a strength model for the cocured stepped lap joints under tensile loading. Compos Struct 32(1995) 593-600.

[38] Ichikawa K, Shin Y, Sawa. A three-dimensional finite-element stress analysis and strength evaluation of stepped-lap adhesive joints subjected to static tensile loadings Int J Adhes Adhes 28(2008) 464-470.

[39] Salih Akpinar, The strength of the adhesively bonded step-lap joints for different step Numbers Composites: Part B 67(2014) 170-178

[40] Hart-Smith L. Adhesive-bonded scarf and stepped-lap joints, Tech. Rep. NASA CR 112237, Langley Research Center, Hampton: VA. 1973.

[41] Bendemra H, Compston P, Phillip J. Crothers Optimisation study of tapered scarf and stepped-lap joints in composite repair patches. Composite Structures 130(2015) 1-8 
[42] Hazell, P.J., Kister, G., Stennett, C. Bourque, P. \& Cooper, G. Normal and oblique penetration of woven CFRP laminates by a high velocity steel sphere. Composites 39(2008) 866-874. 
2017-05-25

\section{Analysis of the effect of impact damage on the repairability of composite panels}

Alzeanidi, Nasser

Elsevier

N. Alzeanidi, H. Ghasemnejad, Analysis of the effect of impact damage on the repairability of composite panels, Composite Structures, Volume 176, 15 September 2017, pp304-312

http://dx.doi.org/10.1016/j.compstruct.2017.05.054

Downloaded from Cranfield Library Services E-Repository 